\title{
Techniques for Differentiating Motor and Sensory Fascicles of a Peripheral Nerve-A Review
}

\author{
Pawan Agarwal $^{1} \quad$ Jitin Bajaj ${ }^{2}$ Dhananjaya Sharma ${ }^{3}$ \\ 1Plastic Surgery Unit, Netaji Subhash Chandra Bose Government \\ Medical College, Jabalpur, Madhya Pradesh, India \\ 2Department of Neurosurgery, Super Specialty Hospital, Netaji \\ Subhash Chandra Bose Government Medical College, Jabalpur, \\ Madhya Pradesh, India \\ ${ }^{3}$ Department of Surgery, Netaji Subhash Chandra Bose Government \\ Medical College, Jabalpur, Madhya Pradesh, India \\ Indian J Neurotrauma:2020;17:28-32
}

\author{
Address for correspondence Pawan Agarwal, MCh, 292/293, \\ Napier Town, Jabalpur, 482001, Madhya Pradesh, India \\ (e-mail: drpawanagarwal@yahoo.com).
}

\author{
Abstract \\ Keywords \\ - anastomosis \\ - electrophysiology \\ - histochemistry \\ - peripheral nerve injury \\ - sensory \\ - motor \\ - fascicles
}

Differentiating motor and sensory fascicles before anastomosis is essential for achieving an excellent postoperative functional outcome for peripheral mixed nerves injuries. However, identifying them is not easy. There are several techniques to address this important issue. Each identifying technique has its own pros and cons; this narrative review highlights the salient features of each of these. Many of the newer techniques need to be tested in humans before they can be recommended for regular use; till then we have to rely mainly on per operative electrical stimulation of nerve to differentiate between sensory and motor fascicles to improve postoperative functional outcome.

\section{Introduction}

End-to-end nerve repair remains the treatment of choice for peripheral nerve injuries. Differentiation of sensory and motor fascicles is needed in peripheral nerve repair and for sensory or motor neurotization to achieve good functional results. ${ }^{1}$ The obvious reasons for poor functional recovery without matching the sensory and motor fascicles are axonal loss and less number of axons reinnervating the target tissues. Many techniques have been developed for differentiating the sensory and motor fascicles, and each has its advantages and disadvantages. A perfect technique is still an elusive one. This narrative review highlights the available techniques for identifying sensory and motor fascicles based on the available literature.

\section{Materials and Methods}

Authors did a literature search using these keywords: differentiation of sensory and motor fascicles, topography, choline acetyltransferase (CT), carbonic anhydrase, electrophysiology, histochemistry, immunohistochemical staining, evoked potentials, and spectroscopy, on PubMed and Google Scholar. Relevant articles were chosen, and this narrative review is based on them.

\section{Results and Discussion}

The primary goal of nerve repair is to allow reinnervation of the target organs by guiding regenerating sensory and motor in the distal stump with minimal loss of axons at the suture line. Complete restoration after peripheral nerve repair is rarely accomplished as all the new axons may not get myelinated to become functional mature fibers and make contact with the appropriate motor and sensory end organs..$^{2-4}$ Many factors, including surgical technique, type of injury, age of the patient, and end-organ survival influence the functional result following nerve repair. Out of all these factors, only the surgical technique is controllable to achieve good results in mixed peripheral nerve repair. It is well known that matching sensory and motor fascicles in the repair of severed mixed nerve yields better functional results. ${ }^{1,5}$ Though it is preferable to align sensory and motor fibers in all injuries to get better results, but proximal injuries and injuries proximal to
DOI https://doi.org/

$10.1055 / \mathrm{s}-0040-1713458$

ISSN 0973-0508.
License terms

(ㅇ)(1) $\Theta \circledast$ 
an emerging motor branch are considered as best for motor sensory differentiation. In a mixed nerve, motor fascicles form a few centimeters before they leave the main trunk and minimal twisting of the nerve trunk often occurs, which leads to difficulty in aligning the motor and sensory fascicles accurately. ${ }^{6,7}$

The methods available to identify motor and sensory fascicles at the nerve stump are limited, and each technique has its pros and cons. Presently four techniques are available for fascicular motor sensory differentiation: anatomic (topography) ${ }^{6}$ electrophysiologic, ${ }^{8}$ histochemical, ${ }^{9}$ and immunohistochemical ${ }^{10}$ (-Table $\mathbf{1}$ ).

\section{Anatomic (Topography)}

Sunderland in 1945 showed the anatomical intraneural topographic distribution of funiculi in radial, ulnar, and median nerves. It was an exhaustive description but it does not have a practical utility in clinical practice. ${ }^{6}$ An intraneural topographic knowledge provides basic information to aid correct coaptation of fascicular groups. However, intraoperative identification and segregation of the sensory and motor fascicles is not practical because trauma distorts the cut end of the nerves and the anatomic position of fascicles are not constant between individuals, and can change significantly over a short distance. Moreover, in late cases, fascicular pattern is distorted due to fibrosis; and hence, it is suitable only in acute and distal injury where pattern of sensory and motor fascicles appears to be more obvious. Therefore, differentiation between motor or sensory fascicles by reference to an anatomic topographic atlas is not dependable.

\section{Electrophysiology}

Various electrophysiological methods have been applied during the course of an operation, including stimulation of the dissected fascicles of the distal and proximal stumps. Studies have shown improved sensory and motor functions after peripheral nerve repair using direct stimulation of nerve. ${ }^{8,11,12}$ Per operatively the motor response can be elicited from the distal stump in general anesthesia without giving relaxants. The sensory response can be noted only in awake conditions when proximal stump is stimulated, and the patient is asked to name the sensory dermatome on which the burning or tingling sensation is felt. A cross-sectional nerve map can be made.

However, electrophysiological methods require local/ awake anesthesia, it can be imprecise or unpleasant for patients and sensory and motor fascicles is testable only in recent injuries. In chronic injuries, due to Wallerian degeneration, motor fascicles are difficult to test. If the surgery and mapping are done within six days of injury, then the identification of distal stump can be made in more than $75 \%$ cases and proximal stump in more than $90 \%$ cases. The technique can be used in both severed as well as intact nerves. ${ }^{11,12}$ Electrical fascicular orientation has several advantages. It is rapid, does not require specialized equipment, and may be used in both partial and complete lesions. However, children, the elderly, and patients with disturbed consciousness may not be able to adequately contribute their response with this technique.

Another electrophysiological method is elicitation of $\mathrm{H}$ Reflex and M wave. ${ }^{13}$ The electrical stimulation is given through a needle electrode directly to the mixed nerve which

Table 1 Advantages and disadvantages of different techniques

\begin{tabular}{|c|c|c|c|c|}
\hline S. No. & Method & Advantages & Disadvantages & $\begin{array}{l}\text { Use in intact } \\
\text { nerve fascicles }\end{array}$ \\
\hline 1. & Topography & $\begin{array}{l}\text { Low cost } \\
\text { Rapid }\end{array}$ & Limited practical utility & Not possible \\
\hline 2. & $\begin{array}{l}\text { Electrophysiology } \\
\text { - Direct stimulation } \\
\text { - H reflex } \\
\text { - M wave }\end{array}$ & $\begin{array}{l}\text { Easy } \\
\text { Fast } \\
\text { In vivo } \\
\text { Good for recent injuries }\end{array}$ & $\begin{array}{l}\text { Needs patient cooperation/awake } \\
\text { anesthesia } \\
\text { Difficult for late injuries } \\
\text { Moderate sensitivity and specificity } \\
\text { Requires electromyography } \\
\text { equipment with a nerve stimulator }\end{array}$ & Possible \\
\hline 3. & $\begin{array}{l}\text { Histochemistry } \\
\text { - Acetylcholinesterase } \\
\text { - Carbonic anhydrase } \\
\text { - choline acetyltransferase }\end{array}$ & High accuracy & $\begin{array}{l}\text { Long Incubation time } \\
\text { Requires exposed nerve tissue } \\
\text { Not useful for late injury }\end{array}$ & Not possible \\
\hline 4. & $\begin{array}{l}\text { Physical methods } \\
\text { - Raman/near Infrared spectroscopy } \\
\text { - Radioisotope methods } \\
\text { - Evoked potentials }\end{array}$ & $\begin{array}{l}\text { High sensitivity and } \\
\text { specificity } \\
\text { Fast }\end{array}$ & $\begin{array}{l}\text { Complex calculations } \\
\text { Susceptible to artifacts } \\
\text { Expensive equipments }\end{array}$ & Possible \\
\hline 5. & Immunohistochemistry & $\begin{array}{l}\text { Fast } \\
\text { Accurate }\end{array}$ & $\begin{array}{l}\text { Complex, requiring incubation } \\
\text { No tissue-specific proteins marker } \\
\text { different nerve fascicles. }\end{array}$ & Not possible \\
\hline 6. & $\begin{array}{l}\text { Newer methods } \\
\text { Quantum dots } \\
\text { MRI with DTI and DWI }\end{array}$ & $\begin{array}{l}\text { High sensitivity and } \\
\text { specificity } \\
\text { Fast } \\
\text { Noninvasive }\end{array}$ & Not tested clinically & Possible \\
\hline
\end{tabular}

Abbreviations: MRI, magnetic resonance imaging; DTI, diffusion tensor imaging; DWI, diffusion weighted imaging. 
tests the integrity of the complete reflex arc, including the afferent Ia fibers, spinal segment, efferent motor fibers, and neuromuscular junction, leading to muscle twitch in the electromyography. At low-intensity stimulation (1-1.5 mV), the $\mathrm{H}$ reflex appears because the sensory fibers have a low threshold and are preferentially stimulated. As the stimulus intensity increases, the $\mathrm{H}$ reflex disappears and the $\mathrm{M}$ wave starts appearing. It is because at the higher intensity the motor fibers get stimulated which propagate orthodromically giving an $\mathrm{M}$ wave and antidromically canceling the $\mathrm{H}$ reflex wave. $\mathrm{H}$ reflex/M wave technique can be used in intact nerves only. Other drawbacks include requirement of awake anesthesia electromyography equipment with a nerve stimulator, have a moderate accuracy for recent injury, and not useful for late injuries. The false reading may occur due to joint effusion, voluntary contraction, and with age. ${ }^{14}$ Therefore, it is of very limited practical utility.

\section{Histochemistry}

Acetylcholinesterase and $\mathrm{CT}$ are present predominantly in motor fibers, and scantly in sensory fibers in a ratio of $8: 1$. Therefore, their presence can be used as a biomarker for different nerve fascicles. ${ }^{15}$ Similarly, carbonic anhydrase activity is higher in sensory fascicles as compared with motor ones. ${ }^{16}$ These chemicals can be detected by direct coloring method. ${ }^{17}$ The enzymatic activity under light microscopy will be shown as brown staining. Histochemical methods take long incubation time ( $24 \mathrm{~h}$ ) forcing the surgery to be done in two stages which makes this method impractical for clinical uses. If the incubation time is brought down, sensitivity of the method gets reduced. ${ }^{18,19}$ Histochemistry has been used in experimental as well as clinical studies but has limited applicability because it requires a specialized technique, a trained team, and expensive equipment. This technique requires cut end of nerve tissue and, thus, cannot be tested on intact nerves..$^{16,20}$ Wallerian degeneration occurs after peripheral nerve injury, which results in a reduction of enzyme activities in the distal nerve stump, rendering this technique not useful in late cases. $^{21}$

\section{Immunohistochemical Staining}

The annexin $\mathrm{V}$ and agrin are special substances of sensory and motor nerves, respectively, and can act as specific antigens for identifying different nerve fascicles. It is a rapid method with high accuracy. Meng et $\mathrm{al}^{22}$ showed that the sensory fibers give red fluorescence under light microscopy. Immunohistochemical staining is complex, requiring tissue fixation, staining, and microscopic observation of nerve. Currently, there are no tissue-specific proteins that can be used as label markers in identifying different nerve fascicles by immunohistochemistry. Thus, these methods have not been easily applied to the clinical setting.

\section{Physical methods}

Raman spectroscopy was discovered by Sir CV Raman, in 1928 , and has been used clinically since 1960 . Spectroscopy can identify different proteins tagged as antigens to sensory and motor fascicles. Wang et $\mathrm{a}^{23}$ showed the Annexin $\mathrm{V}$ tags for sensory and the Agrin tags for motor fascicles with a sensitivity and specificity of 80 to $90 \%$. Raman spectra show significant differences in the spectral properties, such as the intensity and breadth of the peak between motor and sensory fascicles. Near infrared reflectance (NIR) spectroscopy uses variations in the spectral pattern of fascicles. In combination with the cluster analysis, it can differentiate the two types of fascicles. Xie et $\mathrm{al}^{24}$ demonstrated an accuracy of $87.5 \%$ with this technique for differentiating anterior and posterior roots of cauda equine in dogs. Raman spectroscopy and NIR spectroscopy are fast methods but inaccurate, difficult to perform in the operating room, require expensive equipments, and complex calculations. ${ }^{25}$

CT activity demonstration is a radioisotope technique for identification of sensory and motor fascicles. ${ }^{15,26}$ This technique requires taking of nerve samples, incubation, and measurement of the CT activity in a scintillation counter which takes approximately 60 minutes to perform. This method can be used only within few months of injury. ${ }^{27}$

Motor evoked potential (MEP) and somatosensory evoked potential (SSEP) can differentiate between sensory and motor fascicles in animals. ${ }^{28,29}$ In MEP, the stimulation is given at the $\mathrm{C} 3 / \mathrm{C} 4$ region of the cortex and descending orthodromic nerve action potentials (NAP) can be recorded individually from the separated sensory and motor fascicles of a nerve. The differentiation can be made by noting that the NAP from motor fibers is usually biphasic, short duration, and 3 to 8 times in amplitude than the sensory fibers. However, this method cannot be used on intact nerve trunks, require local anesthesia, and are not precise enough to be effective during surgery.

The ideal technique to differentiate between motor and sensory fascicles intraoperatively should be rapid, accurate, noninvasive, applicable to cut as well as intact nerves, useful in early as well as late cases, and should not require awake anesthesia which may be inconvenient to patient. Currently, no technique fulfills these criteria; therefore, many techniques have been tried in vivo as well as in vitro.

The newer methods like quantum dots (QD), diffusion tensor imaging (DTI), and proteomic methods are potentially feasible methods to differentiate between motor and sensory fascicles of the peripheral nerve. QD are "artificial atoms" that possess unique optical properties and emit fluorescence. QD labeling is rapid and accurate method for identification of motor and sensory nerve fascicles, especially during surgery. ${ }^{22}$

Magnetic resonance imaging, particularly DTI, along with fiber tracking, can delineate the distal peripheral nerves from its peripheral terminal branches to the site of the lesion. ${ }^{30,31}$ DTI can also visualize the regeneration of axons after an injury in animal experiments. ${ }^{32}$ Motor and sensory fascicles in peripheral nerves have unique proteomic profiles. Comparing the profiles of normal sensory and motor fascicles to those of recently injured fascicles could lead to the demarcation of specific proteins that may further help in the identification of motor and sensory fascicles by proteomic methods. However, none of these methods has been used clinically for the identification of motor and sensory nerve 
fascicles. More animals and humans studies are required to find the appropriate biomarkers and to clinically appraise the exact performance of procedures.

Currently, the most practical method to differentiate sensory and motor fascicles peroperatively is electrophysiology. Other methods like histochemistry, immunohistochemical staining, and spectroscopy are, at the moment, research tools. The newer methods like QD immunostaining and proteomic methods, though promising, still have to prove their clinical utility.

\section{Conclusion}

There are several promising techniques, but no perfect one, to differentiate the motor and sensory fascicles intraoperatively. All techniques have their advantages and limitations. Many of the newer techniques need to be tested in humans before they can be recommended for regular use; and till then, we have to rely mainly on peroperative electrical stimulation of nerve to differentiate between sensory and motor fascicles to increase the success rate of nerve repair which significantly improves postoperative functional outcome.

\section{Note}

Manuscript was not presented in a meeting or conference.

\section{Conflict of Interest}

None.

\section{Funding}

This research did not receive any specific grant from funding agencies in the public, commercial, or not-for-profit sectors.

\section{References}

1 Deutinger M, Girsch W, Burggasser G, et al. Peripheral nerve repair in the hand with and without motor sensory differentiation. J Hand Surg Am 1993;18(3):426-432

2 Carlstedt T, Lugnegard H, Andersson M. Pacinian corpuscles after nerve repair in humans. Periph Nerve Repair Regen. 1986; $1: 37-40$

3 Dellon AL. Wound healing in nerve. Clin Plast Surg 1990;17(3): 545-570

4 Nampo H, Masaki H, Noma H. An ultrastructural study of sensory nerve endings after neurorrhaphy. J Reconstr Microsurg $1991 ; 7: 363$

5 Höke A, Redett R, Hameed $H$, et al. Schwann cells express motor and sensory phenotypes that regulate axon regeneration. J Neurosci 2006;26(38):9646-9655

6 Sunderland S. The intraneural topography of the radial, median and ulnar nerves. Brain 1945;68:243-299

7 Freilinger G, Gruber H, Holle J, Mandl H. Zur methodik der "senso-motorisch" differenzierten Faszikel-naht peripherer nerven. Handchirurgie 1975;7(3):133-137

8 Hakstian RW. Funicular orientation by direct stimulation. An aid to peripheral nerve repair. J Bone Joint Surg Am 1968;50(6):1178-1186

9 Gruber H, Freilinger G, Holle J, Mandl H. Identification of motor and sensory funiculi in cut nerves and their selective reunion. Br J Plast Surg 1976;29(1):70-73

10 Hietanen M, Pelto-Huikko M, Rechardt L. Immunocytochemical study of the relations of acetylcholinesterase, enkephalin-, substance P-, choline acetyltransferase- and calcitonin gene-related peptide-immunoreactive structures in the ventral horn of rat spinal cord. Histochemistry 1990;93(5):473-477

11 Kato H, Minami A, Kobayashi M, Takahara M, Ogino T. Functional results of low median and ulnar nerve repair with intraneural fascicular dissection and electrical fascicular orientation. J Hand Surg Am 1998;23(3):471-482

12 Gual JS Jr. Electrical fascicle identification as an adjunct to nerve repair. J Hand Surg Am 1983;8(3):289-296

13 Hoffmann P, Beitrage zur Kenntnis der menschlichen Reflex emit besonderer Berucksichtigung der elektrichen. Erscheinnungen. Arch-Physol;1910;1:223-246

14 Palmieri RM, Ingersoll CD, Hoffman MA. The Hoffmann reflex: methodologic considerations and applications for use in sports medicine and athletic training research. J Athl Train 2004; 39(3):268-277

15 Hattori Y, Doi K, Kaneko K, Heong TS. Intraoperative measurement of choline acetyltransferase activity to evaluate the functional status of donor nerve during reinnervated free muscle transfer: a preliminary report. J Hand Surg Am 1998;23(6):1034-1037

16 Riley DA, Sanger JR, Matloub HS, Yousif NJ, Bain JL, Moore GH. Identifying motor and sensory myelinated axons in rabbit peripheral nerves by histochemical staining for carbonic anhydrase and cholinesterase activities. Brain Res 1988;453(1-2): 79-88

17 Karnovsky MJ, Roots L. Adirectcoloring" thiocholine method for cholinesterases. J Histochem Cytochem 1964;12:219-221

18 Gruber H, Zenker W. Acetylcholinesterase: histochemical differentiation between motor and sensory nerve fibres. Brain Res 1973;51:207-214

19 He YS, Zhong SZ; HeYS. Acetylcholinesterase: a histochemical identification of motor and sensory fascicles in human peripheral nerve and its use during operation. Plast Reconstr Surg 1988;82(1):125-132

20 Hattori Y, Doi K, Fukushima S, Kaneko K. The diagnostic value of intraoperative measurement of choline acetyltransferase activity during brachial plexus surgery. J Hand Surg [Br] 2000 25(5):509-511

21 Glass JD, Culver DG, Levey AI, Nash NR. Very early activation of $\mathrm{m}$-calpain in peripheral nerve during Wallerian degeneration. J Neurol Sci 2002;196(1-2):9-20

22 Meng X, Lu L, Wang H, Liu B. Differentiation between the motor and sensory fascicles of the peripheral nerves from adult rats using annexin $\mathrm{V}$-CdTe-conjugated polymer. Neurol India 2011;59(3):333-338

23 Wang H, Ma F, Wang F, Liu D, Li X, Du S. Identification of motor and sensory fascicles in peripheral nerve trunk using immunohistochemistry and micro-Raman spectroscopy. J Trauma 2011;71(5):1246-1251

24 Xie S, Xiang B, Bu S, et al. Rapid identification of anterior and posterior root of cauda equina nerves by near-infrared diffuse reflectance spectroscopy. J Biomed Opt 2009;14(2):024005

25 Preliminary research of indentifying the property of nerve fiber by near-infrared spectroscopy and cluster analysis-Acta Universitatis Medicinalis Nanjing(NaturalScience)2006年05期. http://en.cnki.com.cn/Article_en/CJFDTOTALNJYK200605003. htm. Accessed May 14, 2019

26 Hattori Y, Doi K. Radioisotope technique to evaluate the motor functional status of donor nerve for upper extremity reconstruction. Tech Hand Up Extrem Surg 2004;8(3):189-192

27 Ganel A, Farine I, Aharonson Z, Horoszowski H, Melamed R, Rimon S. Intraoperative nerve fascicle identification using choline acetyltransferase: a preliminary report. Clin Orthop Relat Res 1982;(165):228-232

28 Stober R, Hesse G. [Use of evoked potentials for the intraoperative differentiation of motor and sensory fascicles] Handchir Mikrochir Plast Chir Organ Deutschsprachigen 
Arbeitsgemeinschaft Handchir Organ Deutschsprachigen Arbeitsgemeinschaft Mikrochir Peripher Nerven Gefasse Organ V. 1983;15:232-234

29 Turkof E, Jurasch N, Knolle E, et al. Motor evoked potentials enable differentiation between motor and sensory branches of peripheral nerves in animal experiments. J Reconstr Microsurg 2006;22(7):525-532

30 Skorpil M, Karlsson M, Nordell A. Peripheral nerve diffusion tensor imaging. Magn Reson Imaging 2004;22(5):743-745
31 Hiltunen J, Suortti T, Arvela S, Seppä M, Joensuu R, Hari R. Diffusion tensor imaging and tractography of distal peripheral nerves at 3 T. Clin Neurophysiol 2005;116(10):2315-2323

32 Takagi T, Nakamura M, Yamada $M$, et al. Visualization of peripheral nerve degeneration and regeneration: monitoring with diffusion tensor tractography. Neuroimage 2009;44(3): 884-892 